\title{
ORAÇÃO EM HOMENAGEM AO PROFESSOR WASHINGTON DE BARROS MONTEIRO
}

\author{
Rui Geraldo Camargo Viana \\ Professor Titular do Departamento de Direito Civil da \\ Faculdade de Direito da Universidade de São Paulo
}

Faleceu no dia 13 de abril de 1999, na Capital, aos 88 anos de idade, o professor e desembargador Washington de Barros Monteiro. Natural de Areias (SP), fez seus primeiros estudos em São Paulo, no Grupo Escolar da Várzea do Carmo. Aos dezesseis anos, prestou concurso para a Faculdade de Direito da USP, conquistando o primeiro lugar, posição que manteve durante todo seu curso na velha Academia. Concomitantemente, começou a trabalhar nos Correios. Concluiu o curso de Direito com distinção, sempre obtendo a nota máxima em todas as matérias. Em 1931, aos 21 anos recebeu o diploma. Aprovado em concurso público para o cargo de delegado de Polícia, exerceu essa função na Delegacia de Jogos, em São Paulo, até completar a idade mínima exigida para ingressar, em 1935, na magistratura. Participou ativamente da Revolução Constitucionalista de 1932, tendo combatido na região de Águas da Prata. Em São José do Rio Preto, Taquaritinga, Presidente Venceslau, Barretos e Itapetininga, foi juiz de Direito. Em 1945, nomeado juiz da Primeira Vara da Família e Sucessões da Capital foi promovido (1951) para o Tribunal de Alçada do Estado de São Paulo, onde exerceu a presidência (1952/1953) e (1956/1957). Em 1959, nomeado desembargador do Tribunal de Justiça, entrou em disponibilidade porque o irmão - Raphael já era desembargador e o regimento interno vedava o exercício simultâneo de dois irmãos. Então começou a advogar, abrindo escritório no Prédio Glória, na Praça Ramos de Azevedo. Quando o ilustre irmão foi nomeado ministro do Supremo Tribunal Federal, aposentou-se na Magistratura. Paralelamente, em 1949, descobriria a sua segunda vocação: o magistério. Convidado pelo professor Agostinho Neves de Arruda Alvim para lecionar Direito Civil na Pontifícia Universidade Católica, da primeira turma foi professor e paraninfo. Permaneceu na PUC até 1975, exercendo o cargo de professor titular. Em 1959, conquistou a cátedra de Direito Civil da Faculdade de Direito da USP, em concurso público que teve banca examinadora assim constituída: Vicente Ráo, Serpa Lopes, Caio Mário da Silva Pereira, Orlando Gomes e Jorge Americano. 
Em 1980, foi alcançado pela compulsória, sendo nomeado, no ano seguinte, professor emérito da Faculdade de Direito do Largo de São Francisco. As apostilas esboçadas para os alunos foram transformadas no Curso de Direito Civil (seis volumes), Parte Geral, Direito de Família, Direito das Coisas, Direito das Obrigações ( $1^{\mathrm{a}}$ e $2^{\mathrm{a}}$ partes) e Direito das Sucessões, com cerca de trinta edições publicadas. Deixou de advogar em 1993, ocupando-se apenas dos livros. O desembargador Washington de Barros Monteiro filho do dr. Phidias de Barros Monteiro também magistrado e de d. Erothides de Carvalho Monteiro, pertencentes a famílias de Queluz -, fora casado em primeiras núpcias com d. Benedicta Novaes Monteiro, falecida em 1971, com quem teve duas filhas - Maria Cecília e Ana Cristina. Em segundas núpcias se casou com d. Lucinda Queiroz Monteiro.

Nessa sua fulgurante jornada foi sempre "primus inter pares"

Dele pode-se dizer que alcançou tudo que almejou na vida. Orador primoroso, suas preleções sempre traduziram exercício de eloqüência, cultura e maestria com que mesclava suas lições, sempre escorreitas, do Direito Civil.

Afávèl, simples, sem jamais perder a altivez e o porte de verdadeiro varão de Plutarco, foi, sem dúvidas, na constelação de valores da nossa querida Faculdade, figura solar.

Sua trajetória, na magistratura e no magistério, desenvolveu-se em duas paralelas, retilíneas, sendo difícil detectar em qual delas preexceleu.

Duas vocações que abraçou com amor e coragem, a serenidade da magistratura e a instigante atividade de professor, em ambas realizado, como dá testemunho seu discurso de posse na Cátedra:

"Vivia encerrado nas funções judiciárias que, por irresistivel vocação, elegera na juventude. Não imaginava existir outro mundo. Bastavam-me suas alegrias e seus desencantos, suas flores e seus espinhos. Afinal, era um mundo plano, liso, sem marcos, sem acidentes, mas tranqüilo e feliz.

Certo dia, no entanto, movido por convite do ilustre professor Agostinho Alvim, diretor da Faculdade Paulista de Direito e cujo nome declino com admiração $e$ amizade, principiei a reger, naquele estabelecimento de ensino, uma de suas cadeiras de Direito Civil. 
Descobri, então, surpreendido, que o mundo não se esgotava naquelas remansosas paragens, em que até então me movimentara. Outras regiões, desconhecidas, fascinantes e misteriosas, descortinei à minha frente: o magistério superior, a comunicação intelectual entre professores e alunos, a formação espiritual destes, numa palavra, ser-lhes o iniciador, o mentor de seus estudos." 1

Sua rica experiência judiciária foi de valia extrema e refletida nas lições deixadas em sua obra perene, o Curso de Direito Civil, em seis volumes, alcançando uma vintena de edições.

Seu Curso, anotou o professor Antonio Chaves, "também tem uma personalidade, ou melhor, é um reflexo da personalidade do autor. Se este é simples, informal, acessivel, direto, o produto de sua elaboração não poderia deixar de revelar as mesmas excelsas qualidades. ${ }^{2}$

Abeberando-se sempre das fontes mais puras e mais autorizadas, intercala aqui e ali, como se enrubescendo de dar mostras de sua cultura diversificada, breves oportunas referências às melhores obras de história, de filosofia ou de fição, principalmente francesas $e$ italianas.

Todos os quadrantes da imensa árvore do Direito Civil são percorridos com a mesma segurança e a mesma maestria." 3

Juiz e professor, ditou sempre de Cátedra; se a magistratura o ensinou a amar a Justiça e a odiar a iniqüidade, o magistério revelou-lhe toda a grandeza do

1. Discurso de posse da Cátedra, Revista da Faculdade de Direito, v. LV, p. 388.

2. Antonio Chaves - Saudação ao professor emérito Washington de Barros Monteiro, Revista da Faculdade de Direito, v. LXXV, pp. 248 e ss.

3. Ibidem. 
Direito, que Tobias Barreto ensinou a amar como se ama a liberdade e a senti-lo como se sente o calor e a luz do sol, conforme seu depoimento à ocasião da outorga do título de professor emérito. ${ }^{4}$

Como pôde produzir tanto e com tal brilho?

Por certo porque atento à sua vocação, homem de caráter sem jaça, gerado em família modelar e no lar constituindo sua cidadela, traduzindo com sua vida a lição que fixou em seu Curso:

"Realmente, no seio desta (a família) originam-se e desenvolvem-se hábitos, inclinações e sentimentos que decidirão um dia da sorte do indivíduo. No colo da mãe, assevera Planiol, forma-se o que há de maior e de mais útil ao mundo, um homem honesto.

Foi no seio de sua família, celeiro de virtudes que, à sombra do pai Phidias, magistrado, e do irmão Raphael, outra glória de nossa magistratura e do magistério, acalentou os sonhos que veio a realizar.

Educou suas duas filhas, Maria Cecília e Ana Cristina com acendrado amor e a ajuda constante de sua amada esposa Benedicta e, recasando-se após a viuvez, usufruiu o carinho e a assistência permanente de d. Lucinda.

Ninguém melhor do que ele descreveu o que representou para si, na sua fulgurante trajetória, sua família:

"Como disse Fornari, quando somos adolescentes, a família educa nosso coração. Adultos, ela torna-se escola de moral, afastando-nos as más ações pelo exemplo dos nossos pais, pela honra de sermos casados, a que acresce a força do trabalho. Velhos, impomo-nos

4. Washington de Barros Monteiro, Discurso agradecendo à outorga do título de professor emérito da FDUSP - Revista da Faculdade de Direito, v. LXXV, p. 256. 
a obrigação dos bons exemplos, a fim de que nossos descendentes se tornem melhores do que nós. 5

Ao deixar materialmente o nosso convívio, Washington de Barros Monteiro nos lega o imperecível exemplo de sua vida modelar e, como prenúncio de sua imortalidade, bem poderia parafrasear Ovídio, com relação a seu Curso de Direito Civil:

"Exegi Monumentum Aere Perenius!"

São Paulo, abril de 1999. da FDUSP - Revista da Faculdade de Direito, v. LXXV, p. 259. 


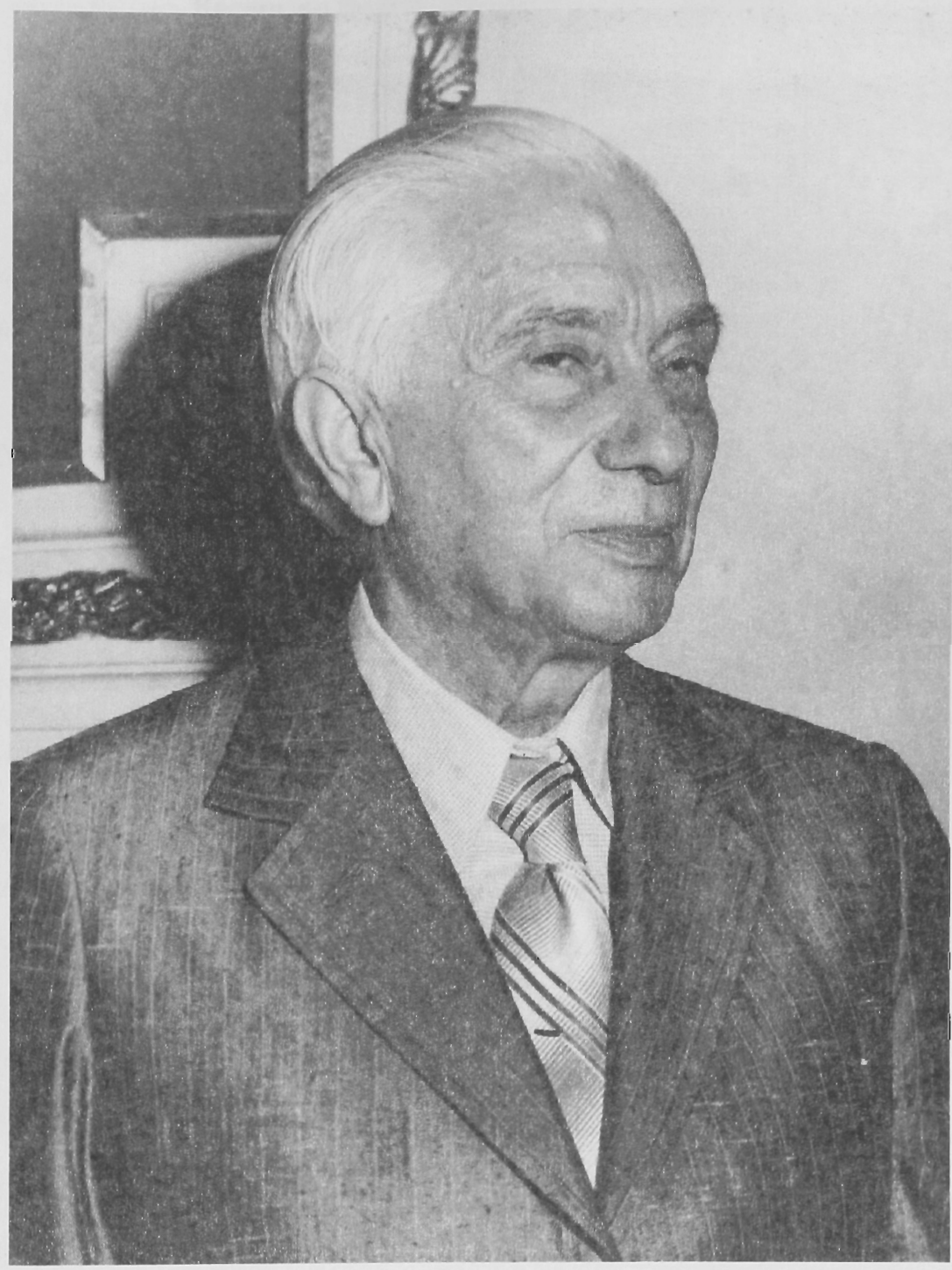

Professor Dr. Washington de Barros Monteiro 